\title{
EDITORIAL
}

\section{Metabolic factors in osteoarthritis: obese people do not walk on their hands}

\author{
Erlangga Yusuf* \\ See related research by Massengale et al., http://arthritis-research.com/content/14/3/R132
}

\begin{abstract}
Obesity is an important risk factor for the development and progression of osteoarthritis (OA). Recently, the paradigm that obesity predisposes people to OA because of extra-mechanical loading only has shifted to the paradigm that metabolic factors (adipokines) are also involved in the pathophysiology of OA. In a cross-sectional study in the previous issue of Arthritis Research \& Therapy, Massengale and colleagues investigated the association between one of the adipokines - leptin - and hand OA. Hand joints are an ideal target to investigate the role of adipokines since they are not weight-bearing. Interestingly, no association with $\mathrm{OA}$ was found, bringing into question a metabolic, rather than a mechanical, explanation for the association between obesity and OA.
\end{abstract}

In the previous issue of Arthritis Research E Therapy, Massengale and colleagues [1] investigate the association between leptin and symptomatic hand osteoarthritis (OA). Leptin is one of the adipokines, an umbrella name for various metabolic factors produced by fat tissue. Excess of fat has long been recognized as an important risk factor for the development and progression of OA. The quite new interest in the metabolic role of fat excess in $\mathrm{OA}$ is boosted by the observation that fat excess is also a risk factor for developing $\mathrm{OA}$ in non-weight-bearing joints, such as those in the hand. The present view is that obesity leads to OA because of not only mechanical but also metabolic effects.

In the investigation of the metabolic effect of fat in OA, hand joints are preferable to hips or knees because the former are not weight-bearing and therefore the metabolic effect does not need to be separated from a

*Correspondence: angga.yusuf@gmail.com

Department of Rheumatology, Leiden University Medical Center, C1-46, Postbus 9600, 2300 RC Leiden, The Netherlands biomechanical effect. However, the number of studies on adipokines in hand OA is very small. In the abovementioned cross-sectional study of more than 1,000 patients, Massengale and colleagues did not find an association between leptin and hand OA. In that study, hand $\mathrm{OA}$ is defined by an algorithm that incorporates symptoms and physical examination. What the authors show is interesting because it challenges the basic science evidence that leans toward the deleterious effect of leptin on cartilage [2], a major tissue involved in OA. Their study is complementary to one of ours: in possibly the only other study of leptin in hand OA, we showed that baseline leptin had no association with the worsening of hand OA on radiographs during 6 years of follow-up [3].

Adiponectin is another adipokine that has received considerable attention in basic research in OA. The three published clinical studies on adiponectin and hand OA separately provide evidence for each of the possible associations: a protective effect, no effect, or a positive damaging effect. Whereas we found that adiponectin was protective against long-term radiographic worsening of hand OA [3], Filková and colleagues [4] showed, in a cross-sectional study, that the serum level of adiponectin was higher in women with erosive hand OA (often considered a particularly severe type of hand OA) than in women with 'usual' hand OA. A cross-sectional study by Choe and colleagues [5] did not find any difference in adiponectin levels of women with hand OA and those of women without it. These results from clinical studies are in line with the results from basic research. At present, there is no agreement that adiponectin is 'good' or 'bad' for joint cartilage. For example, Kang and colleagues [6] demonstrated a catabolic effect of adiponectin on cartilage, whereas Chen and colleagues [7] showed a protective effect.

Efforts to expand our knowledge of adipokines in OA are clearly needed. Additional clinical studies are needed and perhaps should focus on hand OA. Currently, the body of evidence on the role of adipokines in knee OA is stronger than in hand OA. However, although studies on weight-bearing joints allow a better understanding of pathophysiology of fat in OA, separating the metabolic 
from the biomechanical effect of fat excess in weightbearing joints will always be difficult. Large follow-up studies with radiographic hand OA will teach us much about the role of adipokines in OA.

A remark on the measurement of excess of fat should be made. Body mass index, which is commonly used, is actually only a proxy of human body fat. This might explain the conflicting results of studies of obesity and OA. Other ways to assess obesity, such as waist circumference, waist-to-hip ratio, and fat mass [8], should also be used in examining obesity as a risk factor for OA. Since pain is the main reason that patients with OA visit their doctor, the role of adipokines in pain could also be investigated. We can speculate that adipokines might exert their effect on nociceptors in the joints. Basic science studies in OA investigate mostly the effect of adipokines on cartilage, but tissues such as synovium and bone marrow are also involved in OA, so it is also pertinent to explore the effect of adipokines on these tissues.

Interest in the role of adipokines is growing not only in OA but also in atherosclerotic cardiovascular disease [9]. $\mathrm{OA}$ and cardiovascular disease share obesity and increasing age as important risk factors. This has fuelled speculation that $\mathrm{OA}$ and cardiovascular disease are related. Adipokines might stimulate the formation of atherosclerotic plaques that subsequently limit the blood flow to the joint and therefore impair cartilage nutrition. This mechanism is intriguing because, if this hypothesis can be proven, adipokines will be the grand unification theory that relates OA to atherosclerotic cardiovascular diseases [10]. In summary, the story of the role of adipokines in OA continues and there remains optimism that one day we will elucidate the metabolic role of fat in OA since we know that obese people do not walk on their hands.

\section{Abbreviation}

OA, osteoarthritis.
Competing interests

The author declares that he has no competing interests.

Published: 19 July 2012

References

1. Massengale M, Reichmann WM, Losina E, Solomon DH, Katz JN: The relationship between hand osteoarthritis and serum leptin concentration in participants of the Third National Health and Nutrition Examination Survey. Arthritis Res Ther 2012, 14:R132.

2. Simopoulou T, Malizos KN, Iliopoulos D, Stefanou N, Papatheodorou L, Ioannou M, Tsezou A: Differential expression of leptin and leptin's receptor isoform (Ob-Rb) mRNA between advanced and minimally affected osteoarthritic cartilage; effect on cartilage metabolism. Osteoarthritis Cartilage 2007, 15:872-883.

3. YusufE, loan-Facsinay A, Bijsterbosch J, Klein-Wieringa I, Kwekkeboom J, Slagboom PE, Huizinga TW, Kloppenburg M: Association between leptin, adiponectin and resistin and long-term progression of hand osteoarthritis. Ann Rheum Dis 2011, 70:1282-1284.

4. Filková M, Lisková M, Hulejová H, Haluzík M, Gatterová J, Pavelková A, Pavelka K, Gay S, Müller-Ladner U, Senolt L: Increased serum adiponectin levels in female patients with erosive compared with non-erosive osteoarthritis. Ann Rheum Dis 2009, 68:295-296.

5. Choe JY, Bae J, Jung HY, Park SH, Lee HJ, Kim SK: Serum resistin level is associated with radiographic changes in hand osteoarthritis: crosssectional study. Joint Bone Spine 2012, 79:160-165.

6. Kang EH, Lee YJ, Kim TK, Chang CB, Chung JH, Shin K, Lee EY, Lee EB, Song YW: Adiponectin is a potential catabolic mediator in osteoarthritis cartilage. Arthritis Res Ther 2010, 12:R231.

7. Chen TH, Chen L, Hsieh MS, Chang CP, Chou DT, Tsai SH: Evidence for a protective role for adiponectin in osteoarthritis. Biochim Biophys Acta 2006, 1762:711-718.

8. Wang Y, Simpson JA, Wluka AE, Teichtahl AJ, English DR, Giles GG, Graves S, Cicuttini FM: Relationship between body adiposity measures and risk of primary knee and hip replacement for osteoarthritis: a prospective cohort study. Arthritis Res Ther 2009, 11:R31.

9. Lau DC, Dhillon B, Yan H, Szmitko PE, Verma S: Adipokines: molecular links between obesity and atheroslcerosis. Am J Physiol Heart Circ Physiol 2005, 288:H2031-H2041.

10. Conaghan $P G$, Vanharanta $H$, Dieppe $P A$ : Is progressive osteoarthritis an atheromatous vascular disease? Ann Rheum Dis 2005, 64:1539-1541.

doi:10.1186/ar3894

Cite this article as: Yusuf E: Metabolic factors in osteoarthritis: obese

people do not walk on their hands. Arthritis Research \& Therapy 2012, 14:123. 